\title{
THERMAL CONDUCTIVITY AND OTHER PROPERTIES OF CEMENTITIOUS GROUTS
}

\author{
Marita Allan \\ Department of Applied Science \\ Building 526 \\ Brookhaven National Laboratory \\ Upton, NY 11973 \\ (516) 3443060
}

\begin{abstract}
The thermal conductivity and other properties cementitious grouts have been investigated in order to determine suitability of these materials for grouting vertical boreholes used with geothermal heat pumps. The roles of mix variables such as water/cement ratio, sand/cement ratio and superplasticizer dosage were measured. In addition to thermal conductivity, the cementitious grouts were also tested for bleeding, permeability, bond to HDPE pipe, shrinkage, coefficient of thermal expansion, exotherm, durability and environmental impact. This paper summarizes the results for selected grout mixes. Relatively high thermal conductivities were obtained and this leads to reduction in predicted bore length and installation costs. Improvements in shrinkage resistance and bonding were achieved.
\end{abstract}

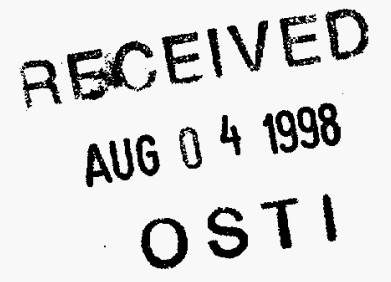

\section{INTRODUCTION}

Key to the successful widespread use of geothermal heat pumps (GHPs) is reduction of installation costs. One way of tackling this is to decrease drilling costs by reducing the required bore length. This, in turn, can be achieved by increasing the thermal conductivity of grout used to seal the annulus between the borehole and heat exchanger loop. The grout provides a heat transfer medium between the U-loop and surrounding formation, controls groundwater movement and prevents contamination of water supply.

Properly designed and mixed cementitious grouts have potential for use as GHP grouts and may prove superior in thermal properties, long term performance and overall economics than bentonite grouts in current use. Cementitious grouts are relatively inexpensive, safe and easy to work with, comprising readily available materials and have a long history of use in geotechnical and civil engineering applications. The simplest cementitious grout consists of cement and water proportioned and mixed to give a fluid consistency. As will be discussed throughout this paper, this type of neat cement grout is not suitable for GHP applications due to lower thermal conductivity, higher shrinkage and other disadvantages when compared with cementitious grouts that contain a filler such as sand.

This project involves characterization of cement-silica sand grouts for thermal conductivity and other properties pertinent to backfilling vertical boreholes for GHPs. Cost analysis and calculations of the reduction in heat exchanger length that can theoretically be achieved with such grouts are being performed by the University of Alabama. Experimental work focuses on optimization of grout formulations in order to improve thermal conductivity while meeting 
requirements for mixing and pumping with conventional equipment, permeability, shrinkage, bonding to U-loop, durability, ease of handling, and economics. This paper describes some of the major results to date. Further details of the research can be found in the FY 97 Progress Report (Allan, 1997).

\section{EXPERIMENTAL}

\section{Materials}

The grouts delineated as having potentially suitable characteristics for GHP applications consist of Type I cement (ASTM C 150), silica sand, water and superplasticizer. Work in FY 97 also examined sulphate resistant cements (Types II and V) and the use of fly ash (FA) and ground granulated blast furnace slag (BFS) as partial replacement for Type I cement in some of the grout formulations. These supplementary cementing materials are recognized for their ability to enhance durability in adverse environments (e.g., aggressive groundwater), reduce heat of hydration and reduce cost. The fly ash conformed to ASTM C 618 Class F. This is a low calcium fly ash produced from combustion of bituminous coal. The blast furnace slag was ASTM C 989 Grade 100.

The superplasticizer (SP) used was a sulfonated naphthalene type with a solids content of $42 \%$ by mass and was supplied by Master Builders (Rheobuild 1000). This chemical admixture functions as a dispersant and increases grout fluidity. Thus, superplasticizer allowed the water content of the grout to be reduced while maintaining pumpability. The aim was to keep the water/cementitious material ratio $(w / c)$ as low as possible in order to improve thermal properties, reduce permeability, and increase durability.

Silica sand was chosen as a particulate filler to increase thermal conductivity of the cementitious grouts. This decision was based on previous data that showed the efficacy of sand for improving thermal properties (Allan and Kavanaugh, 1998), ready availability, low cost, compatibility with grout mixing and placement equipment and ease of use. Different gradations of sand were evaluated in FY 97. Of these, sand conforming to the gradation suggested by ACI Committee 304 (Grading 1) gave the best combined performance. This sand is recommended for preplaced aggregate grouting and the gradation is given in Table 1. The ratio of sand to cementitious material $(\mathrm{s} / \mathrm{c})$ by mass for grouts discussed in this paper was varied from 2.0 to 2.5 . Comparisons were made with neat cement grouts (i.e., no sand added).

A small proportion of Wyoming bentonite was added to some of the cementitious grouts to reduce bleeding, promote full-volume set, and improve sand carrying capacity (i.e., reduce settling). However, use of bentonite was later discontinued in order to simplify the grout mix. An air entraining agent (Master Builders MB-VR) was added to one of the grout mixes used for freeze-thaw tests.

The cementitious grouts were intended to be mixable and pumpable with conventional grouting equipment. The mix proportions of some of the neat cement (Mixes 1 to 3 ) and cementsand grouts covered in this paper are given in Table 2 . The terms $w / c, s / c$ and $\mathrm{SP} / \mathrm{c}$ refer to water/cementitious materials ratio by mass, sand/cementitious material ratio by mass and superplasticizer dosage in $\mathrm{ml} / \mathrm{kg}$ cementitious material, respectively. Mix 5 has a s/c value 


\section{DISCLAIMER}

This report was prepared as an account of work sponsored by an agency of the United States Government. Neither the United States Government nor any agency thereof, nor any of their employees, make any warranty, express or implied, or assumes any legal liability or responsibility for the accuracy, completeness, or usefulness of any information, apparatus, product, or process disclosed, or represents that its use would not infringe privately owned rights. Reference herein to any specific commercial product, process, or service by trade name, trademark, manufacturer, or otherwise does not necessarily constitute or imply its endorsement, recommendation, or favoring by the United States Government or any agency thereof. The views and opinions of authors expressed herein do not necessarily state or reflect those of the United States Government or any agency thereof. 


\section{DISCLAIMER}

Portions of this document may be illegible electronic image products. Images are produced from the best available original document. 
corresponding to two $100 \mathrm{lb}$ bags of sand added for one $94 \mathrm{lb}$ bag of cement. This ratio was chosen for ease of field mixing. Mixes 7 and 8 contain blast furnace slag and fly ash at a cement replacement level of $40 \%$, respectively.

Table 1. Gradation of sand conforming to ACI Committee 304, Grading 1.

\begin{tabular}{||l|c|}
\hline Sieve No. (Size, $\mu \mathrm{m})$ & Percentage Passing $(\%)$ \\
\hline $8(3350)$ & 100 \\
\hline $16(1180)$ & $95-100$ \\
\hline $30(595)$ & $55-80$ \\
\hline $50(297)$ & $30-55$ \\
\hline $100(149)$ & $10-30$ \\
\hline $200(75)$ & $0-10$ \\
\hline
\end{tabular}

Table 2. Mix Proportions of Selected Grouts

\begin{tabular}{|c|c|c|c|}
\hline Mix No. & w/c & s/c & SP/c (m/kg) \\
\hline 1 & 0.4 & 0 & 20 \\
\hline 2 & 0.6 & 0 & 0 \\
\hline 3 & 0.8 & 0 & 0 \\
\hline 4 & 0.5 & 2 & 20 \\
\hline 5 & 0.55 & 2.13 & 15 \\
\hline 6 & 0.6 & 2.5 & 10 \\
\hline $7(40 \%$ BFS $)$ & 0.6 & 2.5 & 10 \\
\hline $8(40 \%$ FA $)$ & 0.6 & 2.5 & 10 \\
\hline 9 & 0.75 & 2 & 0 \\
\hline
\end{tabular}

\section{Thermal Conductivity Measurements}

The cementitious grouts were cast as blocks $75 \mathrm{~mm} \times 125 \mathrm{~mm} \times 25 \mathrm{~mm}$. Three specimens per batch were cast. The blocks were sealed to prevent evaporation, demoulded after 24 hours and placed in a water bath to cure. The hardened grouts were tested for thermal conductivity at an age of 14 days. The grouts were then dried in an oven at $40^{\circ} \mathrm{C}$ over a period of seven days, allowed to $\mathrm{cool}$, and re-tested to determine the effect of loss of moisture.

Thermal conductivity was measured using a Shotherm QTM-D2 Thermal Conductivity Meter. This meter uses the hot wire method to calculate the thermal conductivity, $\lambda$. The hot wire test is a transient method and therefore overcomes the problem of moisture migration and subsequent 
decrease in thermal conductivity that would occur with a steady state method. Further details of the test method are available in the FY 97 Progress Report (Allan, 1997). Three measurements per specimen were made.

\section{Permeability}

The water permeability (hydraulic conductivity) of the grouts under saturated conditions was measured in a flexible wall triaxial cell permeameter on cylindrical specimens. The experimental set up followed that given in ASTM D 5084-90. Two series of permeability tests have been performed to date. The first series was on bulk grouts. The second series was on an annulus of grout cast around an axial length of $25.4 \mathrm{~mm}$ (1 in.) ID. $33.0 \mathrm{~mm}$ OD (1.3 in.) HDPE Driscopipe 5300 (Phillips 66 ). Since the permeameter was originally set up for $76 \mathrm{~mm}$ diameter cylinders, it was not possible to place two lengths of pipe in the specimens. All specimens were insulated for 24 hours after casting so that thermal effects similar to those which may occur in a borehole were simulated. Specimens were demoulded after 24 hours and cured for 28 days in a water bath. The ends of the pipe were plugged before conducting permeability tests so that water would flow either through the grout or between the grout-pipe interface. This indicated how permeability of the grout-pipe system may be influenced by grout shrinkage. The tests were conducted at room temperature. Three specimens per batch were tested.

\section{Bond Strength}

The relative bond strength of selected grouts to HDPE was measured by push out tests. An annulus of grout was cast around an axial length of $25.4 \mathrm{~mm} \mathrm{ID}(1 \mathrm{in}$.), $33.0 \mathrm{~mm}$ OD (1.3 in.) HDPE Driscopipe 5300 (Phillips 66). Mixes $1,6,7$, and 8 were tested. The specimens were placed in a Geotest compression tester with modified platens so that the pipe could be pushed out. Movement of the pipe was monitored with a dial gauge and LVDT. The load required to push the pipe out 1 $\mathrm{mm}(0.04 \mathrm{in}$.) was recorded. Bond strength was calculated as the load divided by the surface area of the embedded pipe. Six specimens per grout batch were tested.

\section{Temperature versus Time}

Concerns have been expressed about the elevated temperatures generated during cement hydration and how this may affect bonding between the cementitious grout and U-loop. Thermal expansion and contraction of the U-loop would occur as the grout temperature increases and subsequently decreases. In order to investigate this issue, the temperature versus time was monitored for simulated boreholes. Tubes were grouted to determine temperature-time profiles and also check for grout pumpability and uniformity of grouting. The tests involved grouting $102 \mathrm{~mm}$ inner diameter $6 \mathrm{~m}$ long insulated Schedule 40 PVC tubes that contained an axial length of $25.4 \mathrm{~mm}$ ( 1 in) $\mathrm{ID}(33.0$ $\mathrm{mm} / 1.3$ in. OD) HDPE Driscopipe ${ }^{\circledR} 5300$. The insulation was $25 \mathrm{~mm}$ thick fibreglass. Thermocouples were embedded in the grout and temperature versus time was monitored with a data logger. One of the tubes was filled with Mix 6 and the other with Mix 7 (slag-modified). The grouts were mixed in a ChemGrout CG-550P paddle mixer and pumped with a piston pump. The temperatures at the grout set time and at the peak of the exotherm were measured. The grouted tubes were later sectioned to examine the microstructure of the grout/pipe interface and the uniformity of grouting throughout the length of the tube. 


\section{Linear Shrinkage}

The procedure used to measure linear shrinkage of the grouts is described in ASTM C 49093a. Grout was cast as beams with of dimensions $50 \mathrm{~mm} \times 50 \mathrm{~mm} \times 286 \mathrm{~mm}(2 \mathrm{in}$. 2 in. $\times 11.25$ in.) and the gauge length between embedded studs was $254 \mathrm{~mm}$ (10 in.). Four specimens per type of grout were cast. The beams were covered with polyethylene to prevent evaporation and plastic shrinkage cracking. After 24 hours the beams were demoulded and measured for length. Following the initial measurement the beams were stored in polyethylene bags so that moisture content was held constant. Change in length was measured using a comparator and monitored for up to 91 days. Neat cement grouts and cement-sand grouts were compared.

\section{Linear Coefficient of Thermal Expansion}

The linear coefficient of thermal expansion of Mix 6 was measured as described in ASTM C 531-85. The same moulds and grout preparation procedure for linear shrinkage tests were used. Four beams were cast and maintained in a polyethylene bag after demoulding. The linear coefficient of thermal expansion (CTE) tests commenced when the beams were 91 days old. The length of the beams was measured at temperatures of 21 and $50^{\circ} \mathrm{C}$ and $\mathrm{CTE}$ calculated.

\section{Bleeding}

Bleeding of cementitious materials occurs when a layer of water forms at the surface of the freshly placed material due to segregation of solids. The amount and rate of bleeding are controlled by mix proportions, ingredients and type of mixing. Bleeding of selected grouts was measured following the procedure given in ASTM C 940-89. The effect of bentonite on grout bleed for one of the mixes was included in the study. An $800 \mathrm{ml}$ quantity of freshly mixed grout was poured into $1000 \mathrm{ml}$ glass volumetric cylinder and covered. The heights of grout and any bleed water were monitored up to 3 hours.

\section{Sulphate Resistance}

The resistance of selected grouts to attack of sodium sulphate was investigated. Cementitious materials are susceptible to degradation by sulphate ions unless precautions are taken and this is a concern if the GHP grouts are exposed to soil or groundwater with a high soluble sulphate concentration. Specifically, precautions must be taken if the soluble sulphate content of soil exceeds $0.1 \%$ or, in the case of water exposure, $150 \mathrm{ppm}$ in water (Kosmatka et al, 1991). Cylinders $76 \mathrm{~mm}$ diameter and $150 \mathrm{~mm}$ long were cast for the sulphate exposure tests. The grouts were superplasticized and had $s / c=2.0$ and $w / c=0.5$ (Mixes 6, 7 and 8). Type I cement based grout was compared with that prepared with Types II (moderate) and V (sulphate resistant) cements.

The cylinders were cured for 28 days in a water bath. Following this, the ends of the specimens were dipped in molten wax and the specimens were placed in a bath of $50 \mathrm{~g} / 1(0.35 \mathrm{M})$ $\mathrm{Na}_{2} \mathrm{SO}_{4}$. The purpose of wax coating the ends of the specimens was to promote radial diffusion of sulphate ions. The $\mathrm{Na}_{2} \mathrm{SO}_{4}$ solution was replaced on a monthly basis to ensure maintenance of the $\mathrm{SO}_{4}^{2-}$ concentration. The $\mathrm{pH}$ was not controlled. The specimens were visually inspected for degradation every two weeks. 


\section{Environmental Impact}

Environmental impact of the grouts in terms of water quality was determined. Leaching of fresh and hardened grout constituents in water was examined for Mixes 6,7 and 8. The experimental arrangement consisted of a $2 \mathrm{~kg}$ layer of washed and dried 20-30 Standard Ottawa sand (ASTM C 190), a $5 \mathrm{~kg}$ layer of grout, another $2 \mathrm{~kg}$ layer of washed and dried 20-30 Standard Ottawa sand, and a $2 \mathrm{~kg}$ layer of deionized water all confined within a polyethylene lined vessel. The top layer of sand and the deionized water were placed immediately after the grout. Hence, the impact of the grout in the unhardened state was included. The arrangement is based on a set up described by Widmann (1996). The first change of water was at 7 hours after placing the grout and other materials. Subsequently, water was changed at intervals of $1,7,14,21$ and 28 days. The $\mathrm{pH}$ of the water was measured. Samples for heavy metal analysis were first acidified to a $\mathrm{pH}<2$ with nitric acid to prevent precipitation. Analysis was performed using inductively coupled plasma-mass spectroscopy (VG Elemental Plasma Quad).

\section{Freeze-Thaw Durability}

The resistance of cementitious grouts to freeze-thaw cycles was measured following ASTM C 666. Mix 5, with and without and an air entraining agent, was cast as beams, cured for 28 days in a water bath and subjected to 300 rapid freeze-thaw cycles. The ultrasonic pulse velocity (ASTM C 597) after cycling was measured to determined changes in grout properties.

\section{RESULTS AND DISCUSSION}

\section{Thermal Conductivity}

The thermal conductivities in saturated and dry conditions of selected different neat cement and cement-sand grouts are compared in Figure 1. The mix numbers are those given in Table 2. The error bars indicate the standard deviation. ( $\left.1 \mathrm{~W} / \mathrm{m} . \mathrm{K}=0.578 \mathrm{Btw} / \mathrm{hr} . \mathrm{ft} .{ }^{\circ} \mathrm{F}\right)$.

The figure shows that thermal conductivity of neat cement grouts increases with decreasing $\mathrm{w} / \mathrm{c}$. When the amount of water in the original mix exceeds that required for hydration of cement the excess can be evaporated, thus leaving pores in the hardened grout. High w/c grouts will have greater porosity and lower thermal conductivity than low w/c grouts. The neat cement grout with w/c $=0.8(\mathrm{Mix} 3)$ showed a significant decrease in mean thermal conductivity of $43.2 \%$ on oven drying. Comparison with the superplasticized grout with $w / c=0.4$ (Mix 1) demonstrated that the percentage decrease in thermal conductivity on drying was reduced to $18.7 \%$ by lowering $\mathrm{w} / \mathrm{c}$. 


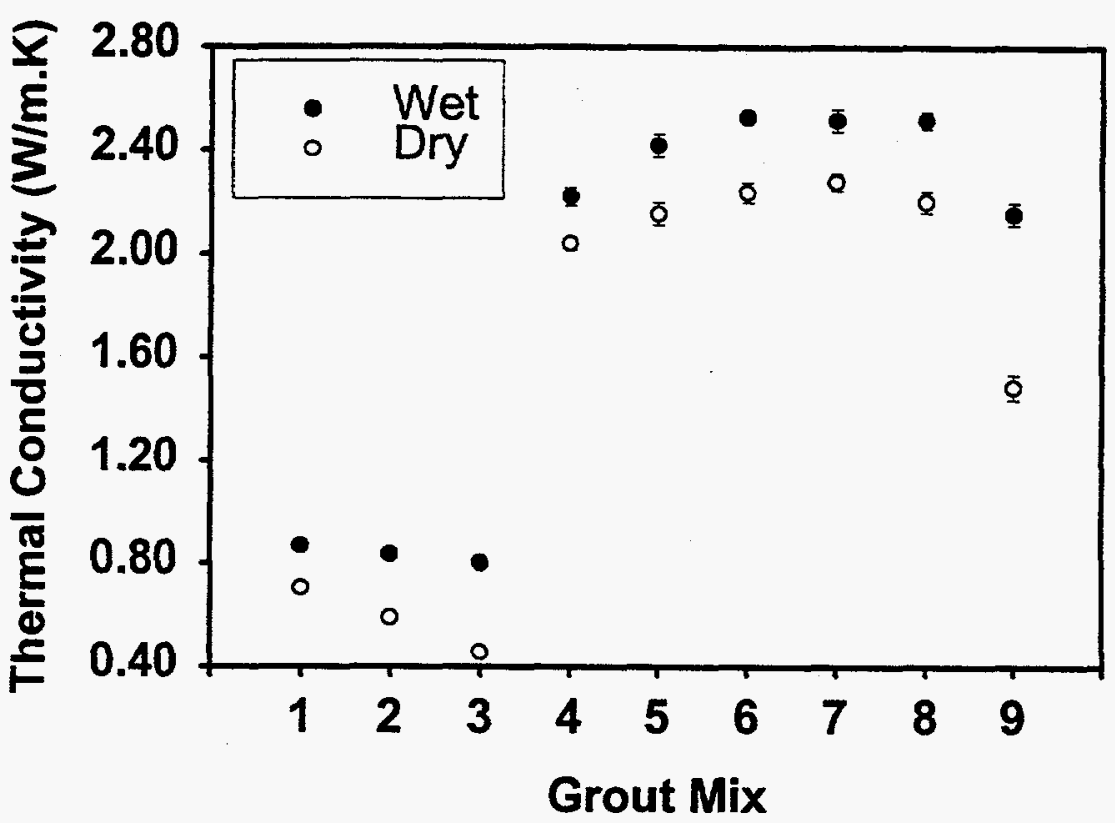

Figure 1. Thermal conductivity of different grouts.

Addition of sand increases the thermal conductivity substantially. The retention of conductivity under drying conditions is also improved and this is beneficial when heat is rejected into the borehole or in arid environments. Loss of conductivity for the cement-sand grouts with $\mathrm{w} / \mathrm{c}=$ 0.5 to 0.6 and $\mathrm{s} / \mathrm{c}=2$ to 2.5 ranged from 8.1 to $11.5 \%$. Mix $9(\mathrm{w} / \mathrm{c}=0.75, \mathrm{~s} / \mathrm{c}=2)$ underwent a decrease in thermal conductivity of $31 \%$. Therefore, this grout, while having a reasonable conductivity in the saturated state, would not perform well if moisture is lost. Selected grouts that had been oven dried were re-saturated and the thermal conductivity was re-measured. It was found that the thermal conductivity returned to its original value. Therefore, the decrease in conductivity on drying of the cement-sand grouts is reversible.

The results can be compared with those for bentonite-based grouts. High solids bentonite grouts that are in current use for backfilling boreholes have thermal conductivities ranging from 0.65 to $0.90 \mathrm{~W} / \mathrm{m} . \mathrm{K}$ (Remund and Lund, 1993). Thermally enhanced bentonite has an increased conductivity of $1.46 \mathrm{~W} / \mathrm{m} . \mathrm{K}$ due to addition of quartzite sand (Remund and Lund, 1993). These values refer to the moist state and significant decreases in conductivity for bentonite grouts occur on drying (Allan and Kavanaugh, 1998). Although not measured, the thermal conductivity of bentonites is probably restored on re-saturation. Heat transfer studies by Braud (1991) and Braud and McNamara (1989) have shown that neat cement grout performs similarly to high solids bentonite grouts. This is in agreement with the relatively low thermal conductivity of the neat cement grouts tested in this work.

\section{Permeability}

The results of bulk versus bonded permeabilities are compared graphically in Figures 2 and 3. The permeability data in Figure 2 demonstrate that increasing w/c from 0.4 (Mix 1 ) to 0.8 (Mix 2) causes an order of magnitude increase in neat cement grout permeability. A dramatic increase in permeability for the grout-pipe specimens is observed for the high w/c of 0.8 . This is attributed to 
a higher permeability pathway at the pipe interface which was confirmed by microstructure studies. For the cement-sand grouts in Figure 3, the value of w/c also controls permeability of the bulk grouts. Fly ash and blast furnace slag have slight effects on permeability. The results show that addition of sand to the grout decreases the permeability of the grout-pipe interface as compared to the neat cement grouts. The permeability of grout-pipe specimens for Mixes 5 and 9 have not been measured. Despite the increase in permeability associated with imperfect bonding, the values are below $10^{-7}$ $\mathrm{cm} / \mathrm{s}$, which is the recommended value for GHP grouts (Eckhart, 1991).

The permeameter is currently undergoing modification to accept $102 \mathrm{~mm}$ diameter specimens that will contain two lengths of HDPE pipe. This will give a better representation of the permeability of a grouted borehole. The effect of thermal cycling on the bond permeability will be investigated.

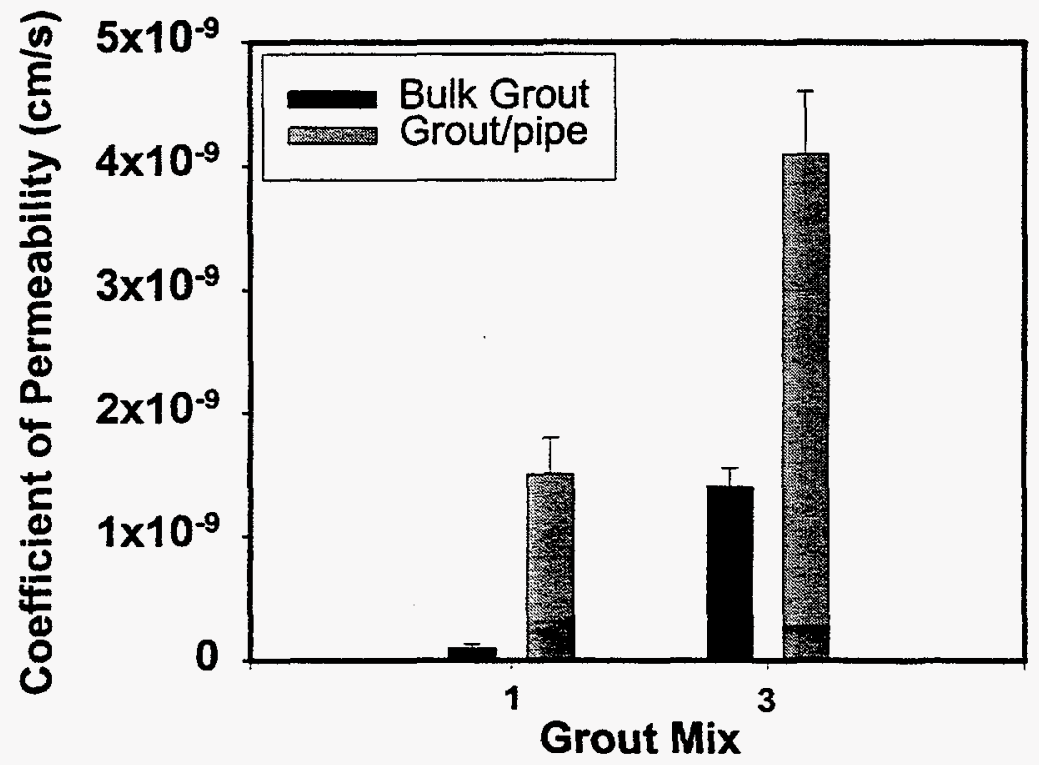

Figure 2. Permeability of neat cement grouts.

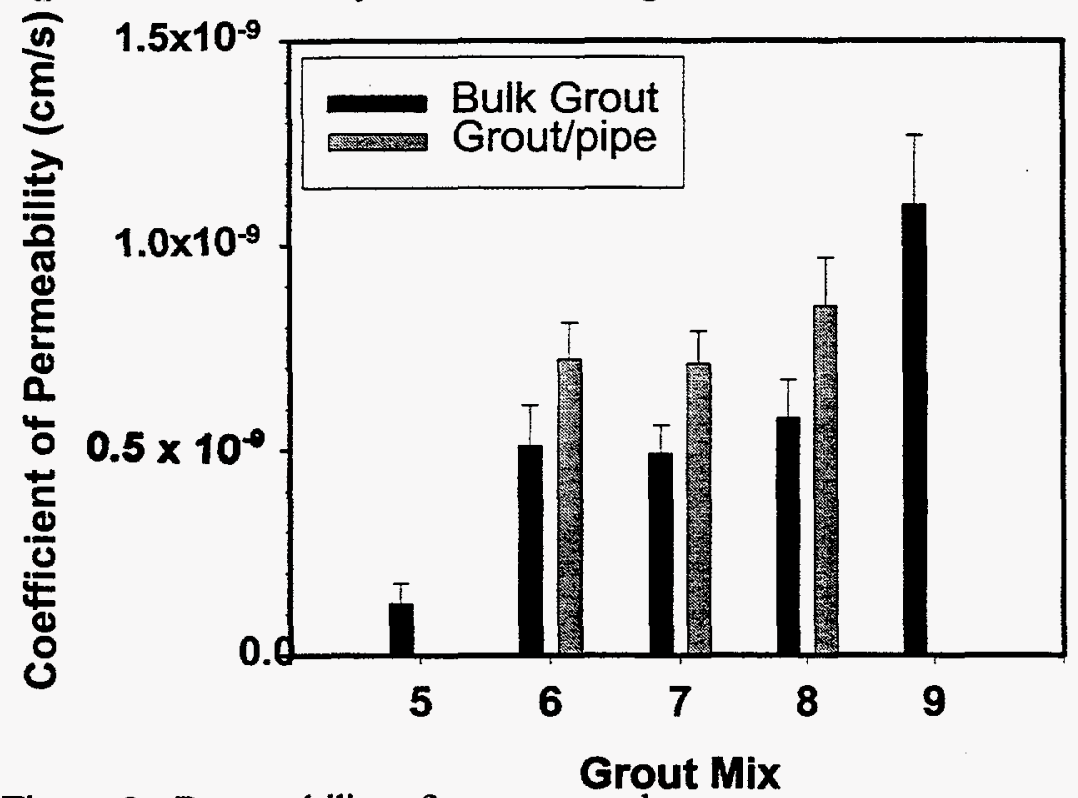

Figure 3. Permeability of cement-sand grouts. 


\section{Bond Strength}

The results of the bond strength tests are presented in Figure 4. The average and standard deviation for six specimens are given. Relatively high shrinkage of superplasticized neat cement results in very low bond strength. Neat cement grout will also have a higher exotherm than a cementsand grout and this will result in greater expansion of embedded HDPE pipe during curing. The bond strengths for Mixes 6 and 7 were virtually the same, despite the lower exotherm of the slag-modified grout. The fly ash-modified grout (Mix 8) had a significantly lower bond strength and this is attributed to higher shrinkage

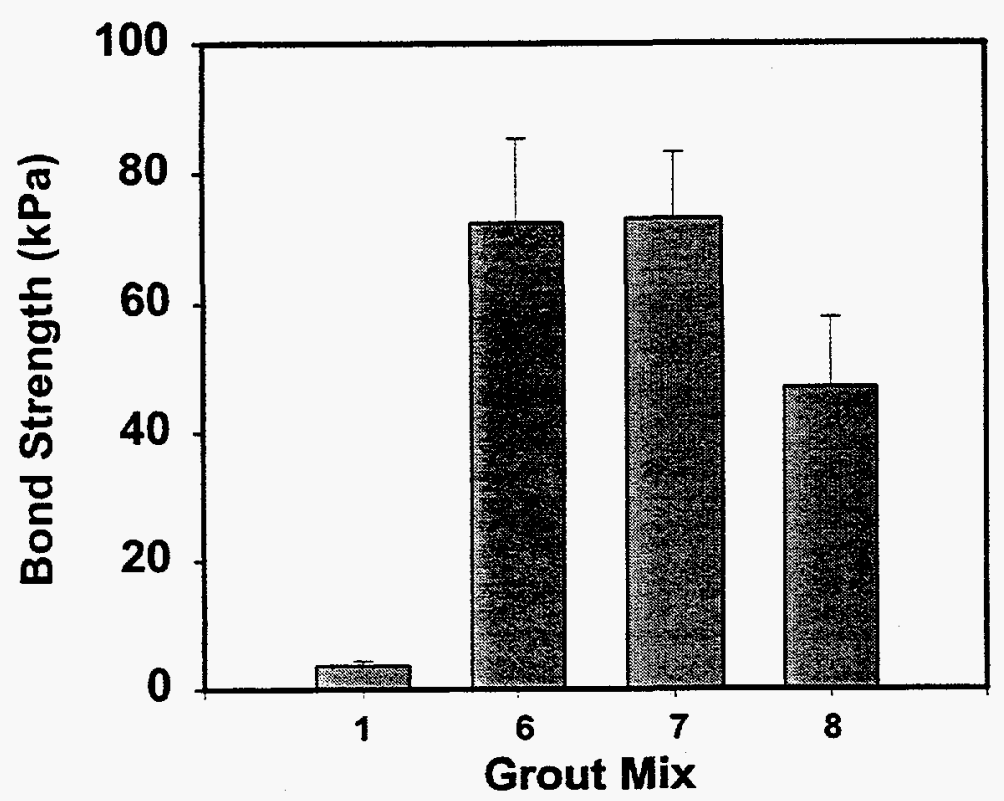

Figure 4. Bond strengths for neat cement and cement-sand grouts.

\section{Temperature versus Time}

Temperature versus time data was obtained for the grout cast in the insulated $6 \mathrm{~m} \times 102 \mathrm{~mm}$ PVC tubes. The ambient temperature during the tests was $17^{\circ} \mathrm{C}$. The peak temperature was $51.2^{\circ} \mathrm{C}$ for Mix 6 and this occurred at an elapsed time of 12 hours and 20 minutes. The set time of this grout was 8 hours and the corresponding temperature at this time was $32^{\circ} \mathrm{C}$. For the slag-modified grout (Mix 7) the peak temperature was $36.7^{\circ} \mathrm{C}$ at 17 hours and 46 minutes after completion of grouting. The set time was 9 hours at which time the temperature was $25.3^{\circ} \mathrm{C}$.

The circumferential coefficient of thermal expansion for the HDPE pipe used is $1.1 \times 10^{-4} /{ }^{\circ} \mathrm{C}$. This can be used to calculate the expansion of the pipe at the set time of the grout. Subsequent cooling of the grout could possibly contribute to imperfect bonding at the grout/pipe interface. The change in circumference of the pipe at $32^{\circ} \mathrm{C}$ is $0.176 \mathrm{~mm}$ and the diameter change is $0.056 \mathrm{~mm}$. For the slag-modified grout, the circumference and diameter changes at the set time are 0.095 and 0.03 $\mathrm{mm}$, respectively. The assumption that the pipe and grout are at the same temperature is a simplification. Hence, the calculated expansions represent maximums for the studied system. Thermal expansion of the grout has been neglected in the calculations. 
Expansion of the HDPE after the grout has set will be confined. The actual amount of expansion that may occur after setting is the focus of further investigation in FY 98 in order to determine how bonding may be improved.

\section{Linear Shrinkage}

The initial and 91 day shrinkage data for the grouts are summarized in Table 3 . The $\%$ length changes are averages for the four beams tested for each grout mix.

Table 3. Shrinkage data for neat cement and cement-sand grouts

\begin{tabular}{|c|c|c|}
\hline Grout Mix & Initial Length Change (\%) & 91 Day Length Change (\%) \\
\hline 1 & -0.216 & -0.343 \\
\hline 2 & -0.163 & -0.278 \\
\hline 3 & -0.505 & -0.591 \\
\hline 5 & -0.220 & -0.275 \\
\hline 6 & -0.202 & -0.263 \\
\hline 7 & -0.234 & -0.265 \\
\hline 8 & -0.237 & -0.257 \\
\hline
\end{tabular}

The results for the unsuperplasticized neat cement grouts (Mixes 2 and 3) show the expected result that high shrinkage is associated with high w/c. This is another reason why it is important to minimize $w / c$ and avoid neat cement grouts for GHP applications. The superplasticized grout with $\mathrm{w} / \mathrm{c}=0.4(\mathrm{Mix} \mathrm{1})$ had higher shrinkage than $\mathrm{Mix} 2(\mathrm{w} / \mathrm{c}=0.6$, no superplasticizer). This indicates that high dosages of superplasticizer are also detrimental to shrinkage resistance.

Incorporation of sand in the grout mix reduces shrinkage. Comparison between Mixes 5 and 6 shows that the grout with higher sand content (Mix 6) has lower shrinkage despite the higher w/c $(0.6$ versus 0.55$)$. The lower shrinkage is also associated with lower superplasticizer dosage.. The impact of reducing the superplasticizer dosage of Mix 5 on shrinkage and pumpability is being studied. Current research is also investigating the shrinkage of grouts exposed to drying conditions. For Mix 5 the drying shrinkage after six weeks in air was $0.445 \%$.

Table 3 also shows that the early shrinkage of grouts with $\mathrm{s} / \mathrm{c}=2.5$ and $\mathrm{w} / \mathrm{c}=0.6$ is increased by addition of blast furnace slag (Mix 7) or fly ash (Mix 8). However, by 91 days the values of shrinkage are similar for this series of grouts.

\section{Microstructure of Grout/Pipe Interface}

Specimens used in the permeability tests were sectioned and viewed under an optical microscope at $50 \mathrm{x}$ magnification to examine the integrity of the grout bond to HDPE. In addition, 
the $6 \mathrm{~m} \times 102 \mathrm{~mm}$ tubes were sectioned for analysis. For the $76 \mathrm{~mm}$ diameter permeability specimens it was found that those grouts without sand had the greatest gaps at the grout-pipe interface. Mix 1 had a gap of 0.02 to $0.4 \mathrm{~mm}$. Such gaps would increase contact resistance and be detrimental to overall heat transfer. Addition of sand to the grouts was found to improve the bond integrity and this concurs with the permeability and bond strength results. Mix 6 exhibited regions where grout was intimately bonded to the pipe. Some discontinuous gaps $0.02 \mathrm{~mm}$ wide were observed. Similar observations were made for the sanded slag-modified grout (Mix 7). Hence, reduction of the exotherm by addition of slag to the mix did not improve bonding. This is attributed to the higher early shrinkage of the slag-modified grout which counterbalances the benefit of decreasing temperature and subsequent expansion of embedded HDPE pipe. The sanded fly-ash modified grout (Mix 8) had a continuous gap at the interface around 0.02 to $0.2 \mathrm{~mm}$ wide, in addition to some voids.

The sections cut from the $102 \mathrm{~mm}$ diameter insulated tubes grouted with Mixes 6 and 7 showed gaps 0.06 to $0.075 \mathrm{~mm}$ wide at the interface, which is greater than that observed on the smaller permeability test specimens. The increased gap width is probably due the higher exotherm experienced in the tubes than in the $76 \mathrm{~mm}$ diameter cylinders.

\section{Linear Coefficient of Thermal Expansion}

The average linear coefficient of thermal expansion for cement-sand grout with $w / c=0.6, \mathrm{~s} / \mathrm{c}$ $=2.5$ and SP/c $=10 \mathrm{ml} / \mathrm{kg}$ (Mix 108) was $1.65 \times 10^{-5} /{ }^{\circ} \mathrm{C}\left(9.17 \times 10^{-6} /{ }^{\circ} \mathrm{F}\right)$. The grout $\mathrm{CTE}$ value can be compared with Driscopipe ${ }^{\otimes}$ which has a linear CTE of $1.2 \times 10^{-4} /{ }^{\circ} \mathrm{F}\left(2.2 \times 10^{-4} /{ }^{\circ} \mathrm{C}\right)$ and a circumferential CTE of $0.6 \times 10^{-4 /} / \mathrm{F}\left(1.1 \times 10^{-4} /{ }^{\circ} \mathrm{C}\right)$.

\section{Bleeding}

The results of the bleed tests on grouts are presented in Table 4. These grouts were prepared in a Hobart mixer. Different results may be obtained with other mixers. The effect of superplasticizer dosage on bleeding for Mix 5 is included.

Table 4. Bleed Test Results

\begin{tabular}{||c|c|c|c|c|c|}
\hline \multirow{2}{*}{ Time (hr) } & \multicolumn{5}{|c|}{ \% Bleed } \\
\cline { 2 - 6 } & $\begin{array}{c}\text { Mix 5 (SP/c } \\
=15 \mathrm{ml} / \mathrm{kg})\end{array}$ & $\begin{array}{c}\text { Mix 5 (SP/c } \\
=12 \mathrm{~m} / \mathrm{kg})\end{array}$ & Mix 6 & Mix 7 & Mix 8 \\
\hline 0.5 & 0.12 & 0.12 & 0.25 & 1.24 & 0.99 \\
\hline 1 & 0.37 & 0.25 & 0.50 & 1.86 & 1.23 \\
\hline 1.5 & 0.50 & 0.25 & 0.62 & 2.48 & 1.85 \\
\hline 2 & 0.62 & 0.37 & 0.62 & 2.61 & 1.97 \\
\hline 2.5 & 0.62 & 0.37 & 0.62 & 2.73 & 2.10 \\
\hline 3 & 0.62 & 0.37 & 0.62 & 2.73 & 2.10 \\
\hline
\end{tabular}


The cement-sand grouts tested were subject to bleeding when mixed in the low shear Hobart mixer unless bentonite was added at an appropriate level. Use of a more efficient high shear mixer would permit reduction of w/c, superplasticizer dosage and bleeding. As shown, reduction of superplasticizer dosage reduces bleeding. If excessive bleeding of cementitious grouts occurs, the problem can be solved by manipulation of the mix proportions, addition of bentonite or use of a better mixer.

\section{Sulphate Resistance}

The cylinders exposed to a sodium sulphate solution were examined periodically for indications of cracking. Mix 6 exhibited surface cracking after four months of exposure. The deterioration progressively worsened. Up to six months the other grouts (Type II cement, Type V cement, Mixes 7 and 8) did not show any visible deterioration. This is in agreement with predicted response and further details on sulphate attack can be found in Neville (1996). It is recommended that measures be taken to prevent sulphate attack of GHP grouts in areas where soils or groundwater have high soluble sulphate content such as reducing w/c, use of sulphate resistant cements or partial replacement of Type I cement with slag or fly ash.

\section{Environmental Impact}

The environmental impact of Mixes 6,7 and 8 was measured in terms of changes in the chemistry of exposed water. The complete results for $\mathrm{pH}$ and concentrations of specific metals in deionized water in contact with the grouts in both the fresh and hardened states are reported elsewhere (Allan, 1997). It was determined that the leachability of elements from the grouts was below the EPA drinking water levels. The $\mathrm{pH}$ of the water increased due to leaching of $\mathrm{Ca}(\mathrm{OH})_{2}$ and this behaviour stabilized with time. Inclusion of slag or fly ash in the grout decreased the alkalinity of the water.

\section{Freeze-Thaw Durability}

Mix 5 without the air entraining agent exhibited slight surface scaling at the competition of the freeze-thaw tests. Air entrained grout did not undergo any visual degradation. The average decrease in ultrasonic pulse velocity of Mix 5 was $7.5 \%$, whereas the air entrained version maintained the same pulse velocity. However, the air entrained grout had a significantly lower thermal conductivity of $1.553 \mathrm{~W} / \mathrm{m} . \mathrm{K}$ due to the introduced air void system which improves freeze-thaw resistance.

\section{Bore Length Design and Grout Costs}

The required bore length depends in part on the thermal conductivity of the backfill grout. Bore length calculations for different grout thermal conductivities, formation geologies and building load have been conducted by senior Mechanical Engineering students at the University of Alabama under the direction of Prof. S. Kavanaugh. Use of cement-sand grouts can significantly reduce the required bore length and thus reduce installation costs. Further details of the findings are provided in the FY 97 Annual Report. The estimated cost of Mix 5 is $\$ 0.626 /$ gallon based on prices of $\$ 5.15 / 94 \mathrm{lb}$ bag of cement, $\$ 3.00 / 100 \mathrm{lb}$ bag of sand and $\$ 5.25 /$ gallon of superplasticizer. Sand prices of $\$ 6.60 / 100 \mathrm{lb}$ bag have also been quoted for small orders. This increases the grout cost estimate 
to $\$ 1.00 /$ gallon. Reduction of the superplasticizer dosage through use of a high shear mixer may be possible and this would decrease the grout cost. This is being explored in current research. In addition, the costs associated with prepackaging the dry ingredients are being investigated.

\section{Grout Mixing}

The relative merits of low shear paddle versus high shear colloidal grout mixers have been discussed by Houlsby (1990), Domone and Jefferis (1994) and Widmann (1996). Paddle mixers are less expensive than colloidal mixers, but also less effective and require greater mixing time. Discharge from the mixing tank to the pump hopper is by gravity and, hence, is slower. The improved sand carrying capacity, decreased water requirement, reduced bleeding and greater flowability of grouts mixed colloidal mixers has been documented previously. Colloidal mixers improve wetting of the cement and sand particles and prevent segregation.

Mixer studies in this work confirmed that a colloidal mixer would be preferred for GHP cement-sand grouts. However, the grouts can also be mixed in a paddle mixer if necessary and if a relatively high $\mathrm{w} / \mathrm{c}$ is used. Irrespective of the mixer used, it is recommended that trial mixes be performed and water or superplasticizer adjusted so that suitable pumpability is achieved. Variations in sand gradations from the sand used in this work will also require trial mixes to determine appropriate $w / c$. Any changes in mix proportions should be documented. It is cautioned that excessive water or superplasticizer beyond that required will be detrimental to properties of the grout such as bleeding, shrinkage, permeability, thermal conductivity, and durability. Therefore, the amounts of water and superplasticizer required for a grout batch be measured accurately.

Colloidal mixers are usually used in conjunction with a larger capacity agitator in which the grout is stored and agitated until use. This is necessary to keep the particles in suspension, and, in the case of thixotropic grouts, keep the grout mobile and fluid. A colloidal mixer-agitator plant is more expensive than a single paddle mixer. The advantages of the plant include shorter mixing time, more rapid discharge, superior mixing, and resultant grout properties. Colloidal mixers are available in a range of capacities (typically 60-127 gallons), including trailer mounted units. Centrifugal pumps or propeller type mixers should not be used for mixing cement-sand grouts since mixing will be unsatisfactory. Concrete ready mix trucks are also inappropriate for mixing of any type of grout.

The procedure for mixing the cement-sand grouts in either a paddle or colloidal mixer is as follows (e.g., Houlsby, 1990):

1. Place required measured quantity of water in mixer.

2. Place required measured quantity of liquid superplasticizer in mixer.

3. Start mixer.

4. Place required measured quantity of fly ash or blast furnace slag in mixer if used.

5. Place required measured quantity of cement in mixer.

6. Place required measured quantity of sand in mixer.

7. Mix grout for specified time. 


\section{Quality Control}

Fresh cement-sand grout can be checked to determine that it meets specifications by performing appropriate quality control tests. These are measurement of specific gravity (ASTM D 854) and flow time (ASTM C 939). Documentation of these properties for each grout batch is sound practice.

\section{FY 98 Activities}

In FY 98 it is planned to conduct two field demonstrations of a grout based on Mix 5 in collaboration with Oklahoma State University and Sandia National Laboratories. In-situ thermal conductivity measurements will be performed and compared with laboratory data. Heat pump performance will be monitored over heating and cooling seasons. The field demonstration will enable quantitative comparison of the selected cement-sand grout with conventional grouts under actual working conditions. Further studies of permeability and bonding of cementitious grouts to U-tube are in progress, including analysis of the effect thermal cycling. Shrinkage tests are being continued for different mix proportions and the properties of commercially available grouts that contain expansive agents are being measured. Collaboration with the University of Alabama to measure thermal resistance per unit length for different grouts in an experimental rig is ongoing.

\section{CONCLUSIONS}

Superplasticized cement-silica sand grouts have thermal conductivities in the range of 2.161 to $2.531 \mathrm{~W} / \mathrm{m} . \mathrm{K}$ ( 1.249 to $\left.1.463 \mathrm{Btu} / \mathrm{hr} . \mathrm{ft} .{ }^{\circ} \mathrm{F}\right)$ for sand/cement ratios by mass of 2 to 2.5 . Cementsand grouts have significantly higher thermal conductivity than neat cement or bentonite grouts and retain conductive properties under drying conditions. The grouts have permeabilities of the order of $10^{-10} \mathrm{~cm} / \mathrm{s}$ and improved bonding characteristics to HDPE U-loop over neat cements. The increase in thermal conductivity is predicted to decrease required bore length, and therefore reduce drilling and materials costs associated with installation of vertically oriented heat exchangers for geothermal heat pumps. The grouts can be mixed in a paddle mixer, although a high shear colloidal mixer would be preferred and could allow reduction of water/cement ratio and superplasticizer dosage. forthcoming field trials will provide information on the in-situ performance of the cement-sand grouts.

\section{ACKNOWLEDGMENTS}

This work was performed under the auspices of the U.S. Department of Energy, Washington, D.C., under Contract No. DE-AC02-98CH10886. Thanks are due to Mr. Lew Pratsch of the Department of Energy/Office of Geothermal Technologies for support of this work.

\section{REFERENCES}

ACI 304.1R, "Guide for the Use of Preplaced Aggregate Concrete for Structural and Mass Concrete Applications", American Concrete Institute Materials Journal, V. 88, No. 6, pp. 650-668, 1991.

M.L. Allan, "Thermal Conductivity of Cementitious Grouts for Geothermal Heat Pumps", BNL 65129, November, 1997. 
M.L. Allan and S.P. Kavanaugh, "Thermal Conductivity of Cementitious Grouts and Impact on Heat Exchanger Length Design for Geothermal Heat Pumps", Submitted to International Journal of HVAC\&R Research, 1998.

H.J. Braud, "Grout Effect in Vertical Heat Pump Bores", Proceedings of International Energy Agency Ground Coupled Heat Pump Conference, 1991.

H.J. Braud and S. McNamara, "Enhancement of Heat Transfer to Earth in Ground Coupled Heat Pump Bores, ASAE/CSAE Meeting, Quebec, 1989.

P.L.J. Domone and S.A. Jefferis (eds), "Structural Grouts", Blackie Academic and Professional, London, 1994.

F. Eckhart, "Grouting Procedures for Ground-Source Heat Pump Systems", Oklahoma State University, Ground Source Heat Pump Publications, 1991.

A.C. Houlsby, "Construction and Design of Cement Grouting", John Wiley and Sons, New York, 1990.

S.H. Kosmatka et al., "Design and Control of Concrete Mixtures", Fifth Edition, Portland Cement Association, 1991.

A.M. Neville, "Properties of Concrete", Fourth Edition, John Wiley and Sons, New York, 1996.

C.P. Remund and J.T. Lund, "Thermal Enhancement of Bentonite Grouts for Vertical GSHP Systems in Heat Pumps and Refrigeration Systems", K.R. Den Braven and V. Mei (Eds.), ASME, 29, pp 95$106,1993$.

R. Widmann (ed), "International Society for Rock Mechanics Commission on Rock Grouting", International Journal of Rock Mechanics and Mining Sciences and Geomechanics Abstracts, V. 33, No. 8, pp. 803-847, 1996. 